\title{
Operant measurement of auditory threshold in prelingually deaf users of cochlear implants: II
}

\author{
Wagner R. da Silva ${ }^{1}$, Deisy G. de Souza ${ }^{1}$, Maria Cecília Bevilacqua ${ }^{2}$ and Jair Lopes Jr. ${ }^{3}$ \\ 1 - Universidade Federal de São Carlos, São Carlos, SP, Brazil \\ 2 - Universidade de São Paulo (Bauru), SP, Brazil \\ 3 - Universidade Estadual Júlio de Mesquita Filho - UNESP/Bauru, SP, Brazil
}

\begin{abstract}
Two experiments evaluated an operant procedure for establishing stimulus control using auditory and electrical stimuli as a baseline for measuring the electrical current threshold of electrodes implanted in the cochlea. Twenty-one prelingually deaf children, users of cochlear implants, learned a Go/No Go auditory discrimination task (i.e., pressing a button in the presence of the stimulus but not in its absence). When the simple discrimination baseline became stable, the electrical current was manipulated in descending and ascending series according to an adapted staircase method. Thresholds were determined for three electrodes, one in each location in the cochlea (basal, medial, and apical). Stimulus control was maintained within a certain range of decreasing electrical current but was eventually disrupted. Increasing the current recovered stimulus control, thus allowing the determination of a range of electrical currents that could be defined as the threshold. The present study demonstrated the feasibility of the operant procedure combined with a psychophysical method for threshold assessment, thus contributing to the routine fitting and maintenance of cochlear implants within the limitations of a hospital setting. Keywords: cochlear implant, simple auditory discrimination, Go/No Go, threshold measurement, deaf children, mouse click
\end{abstract}

Received 25 January 2011; received in revised form 4 June 2011; accepted 8 June 2011. Available on line 15 June 2011

\section{Introduction}

Neurosensory hearing impairment has profound deleterious effects on many kinds of behaviors that require auditory perception, such as those involved in language acquisition, communication, socialization, and academic performance. One technical solution that recovers the possibility of behavioral processes that involve auditory stimulation is the cochlear implant ${ }^{1}$. The implant is an electronic device designed to stimulate the auditory nerve fibers in order to enhance hearing in persons with profound (deafness) to severe inner ear hearing loss when a hearing aid does not provide sufficient auditory input (American Speech-LanguageHearing Association, 2004).

Wagner R. da Silva, Deisy G. de Souza, Instituto Nacional de Ciência e Tecnologia sobre Comportamento, Cognição e Ensino (INCT-ECCE), Universidade Federal de São Carlos, Brazil. Maria Cecília Bevilacqua, (INCT-ECCE) Universidade de São Paulo (Bauru), Brazil. Jair Lopes Jr., Universidade Estadual Júlio de Mesquita Filho - UNESP/Bauru, Brazil. Correspondence regarding this article should be directed to: Deisy das Graças de Souza, Rua Marechal Deodoro, 1645, Apto 11, São Carlos, SP 13560-200, Brazil. Phone: +55 (16) 3351 8459. Fax: +55 (16) 3351 8492. E-mail: ddgs@ufscar. br; or to Wagner R. da Silva, E-mail: roge34_s@hotmail.com
The cochlear implant allows individuals with neurosensory hearing impairment, such as bilateral and profound hearing loss, to detect sounds from the environment, including speech sounds. Implantees then are able to learn and relate the sounds to other environmental events in symbolic networks, such as language (Almeida-Verdu et al., 2008; da Silva, de Souza, de Rose, Bevilacqua, \& Mcilvane, 2006; Svirsky, Robbins, Kirk, Pisoni, \& Miyamoto, 2000; Svirsky, Teoha, \& Neuburger, 2004).

The basic functions of the device include capturing and converting auditory stimuli into electrical current and conducting this current to electrodes inserted within the cochlea, which directly stimulates the auditory nerve (Bevilacqua, Costa Filho, \& Moret, 1997). The equipment has external and internal components. Externally, the implant is composed of a retro-auricular microphone, speech processor, and transmitting antenna. The internal components, which are surgically implanted, include a stimulator-receiver placed over the temporal bone and a set of electrodes arranged in clusters and inserted into the cochlea (Bevilacqua, Costa Filho, \& Moret, 2003; Clark, Cowan, \& Dowell, 1997). The connection between the

\footnotetext{
${ }^{1}$ According to Nicolelis (2001), the cochlear implant was the first successful device for brain-machine interactions.
} 
external and internal implant components is established using two magnets, one installed in the transmitting antenna and the other installed in the stimulator-receiver, keeping the antenna fastened to the individual's head in the location where the stimulator-receiver is implanted. The electrical stimulation process begins in the retroauricular microphone, which captures environmental sounds and transmits them to the speech processor. The speech processor, in turn, selects and encodes the speech and environmental sounds and generates electrical pulses that are sent to the transmitting antenna. Radiofrequency waves conduct the decoded signals and pulses to the internal components. The stimulator-receiver then activates the electrodes, generating electrical current flow on the auditory nerve that, in turn, carries the stimulation to the cortex (Clark et al., 1997; Rizzi, \& Bevilacqua, 2003).

After surgery, the cochlear implant must be adjusted to individual requirements. One of the parameters in the production of auditory electrical stimulation is the amount of electrical current that is sufficient for generating auditory sensation in each electrode, without producing discomfort. To determine this measurement, while programming the device, establishing the minimum and maximum current levels is necessary (i.e., delimiting a dynamic extension area for the electric stimulation; Clark et al., 1997). Because of interindividual variability in the stimulation (Ferguson, Collins, \& Smith, 2003), the current levels must be determined individually. This requires assessment using clinical procedures, in which the clinician must rely on the implantee's oral reports to define (1) the minimum amount of electrical current that produces consistent detection of the stimulus (i.e., electrical threshold) and (2) the maximum amount of current (i.e., electrical comfort level) that can be applied without discomfort (Clark et al., 1997; Thai-Van et. al., 2004). Thus, because the electrical stimulation is accessible only to the user of the cochlear implant (i.e., the sensation is a private event), the programming of the current parameters using software that controls the equipment is highly dependent on the person's auditory experience and preimplantation verbal skills. Among implantees who are prelingually deaf (i.e., who have deafness that occurred prior to the acquisition of oral language) or have little auditory experience prior to implantation (e.g., young children), the linguistic competence for supplying information regarding the auditory sensation produced by the electrical stimulation may be hindered, compromising the reliability of measures obtained through self-reports in clinical tests.

Using operant methods (Skinner, 1953), we developed a procedure that successfully assessed the electrical threshold through the cochlear implant in prelingually deaf children (da Silva, de Souza, Bevilacqua, Kimura, \& Lopes Jr., in press). The procedural features were based on previous studies that applied operant techniques for threshold assessment in nonhuman subjects (e.g., Blough, 1958; Clevenger \& Restrepo, 2006; Gerken \& Sandlin, 1977; Langemann, Gauger, \& Klump, 1998; Pfingst \& Morris, 1993) and young or disabled children (e.g., Berg \& Smith, 1983; Fulton \& Spradlin, 1971; Moore, Wilson, \& Thompson, 1977; Primus \& Thompson, 1985; Sinnott, Pisoni, \& Aslin, 1983). Initially, participants learned a simple successive discrimination task (Go/No Go) between the presence and absence of the auditory stimulus generated by the cochlear implant. Successive trials were presented by a computer, and the operant response consisted of pressing a computer mouse button while positioning its arrow on a green square on the computer's screen. Thus, no vocal or gestural response was required. Pressing the button in the presence of auditory stimulation produced programmed reinforcing consequences, followed by an intertrial interval (ITI) and a new trial. Responding in its absence was followed only by the ITI and the next trial. The target for electrical stimulation was a single electrode located in the cochlea's medial region. When the simple discrimination baseline became stable, the stimulus intensity was manipulated according to an adaptation of the staircase method (Cornsweet, 1962; da Silva \& Ribeiro Filho, 2006; Feitosa, 1996; Gescheider, 1997; Levitt, 1971). The method is a variation of the method of limits (Gescheider, 1997):

One begins by presenting a sequence of stimuli which progressively increase or decrease in value. When the observer's response changes, the stimulus value is recorded, and the direction of the stimulus sequence is reversed from ascending to descending, or vice versa...This procedure continues until a sufficient number of response-transition points has been recorded. The threshold is taken as the average of the transition points. (p. 59)

In da Silva et al. (in press), the procedure began with a descending series, followed by a reversal in ascending order when the discrimination was disturbed. Two or more reversals were conducted, depending on the participant's availability. The absence of responding in the presence of electrical stimulation of a particular intensity indicated a lack of stimulus detection and not a lack of discrimination, given the subsequent recovery of responding when the intensity was increased again. Electrical auditory threshold was defined for implantees according to Clark et al. (1997) as the lowest intensity that maintained the response in $100 \%$ of the opportunities in which the stimulus was presented. Seven children, 5 to 7 years old, learned the auditory discrimination and maintained accurate responding under certain intensities during the descending series. All of the children stopped responding (or pressed the button randomly in both 
the presence and absence of the stimulus) under lower intensities. Reversal to higher intensities restored the discriminated responding, allowing the determination of the lowest intensity interval at which the electrical stimulus was detected.

The present paper describes two studies that assessed the generalizability of the data concerning auditory threshold measurements using the same operant procedure with children who were younger than those who participated in the previous study (da Silva et al., in press). The present studies also extended the assessment to three electrodes, one in each cochlear section (basal, medial, and apical). Study 1 replicated the Go/No Go procedure for teaching the simple successive discrimination between the presence and absence of electrical stimulation applied to the three electrodes. Study 2 introduced some procedural variations, including shorter baseline training, with the goal of solving the specific demands posed by the assessment of young children.

\section{General Methods}

\section{Participants}

The two studies recruited 21 children with prelingual bilateral neurosensory hearing loss who were users of Nucleus $24^{\circledR}$ cochlear implants. During postoperative care, the children were seen periodically at the hospital to monitor or adjust the functioning of the implant. They lived in different cities around Brazil and remained in the hospital for 2 to 3 days (at most) for previously scheduled clinical routines. The threshold assessment was conducted as one of these routines.

Table 1 shows the participants' characteristics relevant to the study. Eight children were female, and 13 were male. Their ages ranged from 4 years to 5 years 11 months. The period of sensorial deprivation ranged from 1 year 10 months to 5 years 4 months. The time since implantation varied from 7 months to 3 years 7 months. These periods corresponded to the children's experience with auditory stimuli at the beginning of each study.

Table 1. Participant characteristics, including age, gender, duration of sensory deprivation, and time interval since implantation at the beginning of each study.

\begin{tabular}{|c|c|c|c|c|}
\hline Participant & $\begin{array}{c}\text { Age } \\
\text { (years; months) }\end{array}$ & Gender & $\begin{array}{l}\text { Sensory deprivation } \\
\text { (years; months) }\end{array}$ & $\begin{array}{l}\text { Time after implantation } \\
\text { (years; months) }\end{array}$ \\
\hline \multicolumn{5}{|c|}{ Study 1} \\
\hline GLR & $4 ; 3$ & M & $2 ; 3$ & $2 ; 0$ \\
\hline GNV & $4 ; 4$ & M & $1 ; 11$ & $2 ; 5$ \\
\hline LHR & $4 ; 5$ & $\mathrm{~F}$ & $3 ; 1$ & $1 ; 4$ \\
\hline RDG & $4 ; 7$ & M & $1 ; 11$ & $2 ; 8$ \\
\hline VTR & $4 ; 10$ & M & $2 ; 11$ & $1 ; 11$ \\
\hline LCD & $4 ; 11$ & $\mathrm{~F}$ & $3 ; 1$ & $1 ; 10$ \\
\hline BRN & $5 ; 2$ & M & $3 ; 1$ & $2 ; 1$ \\
\hline GRL & $5 ; 9$ & $\mathrm{~F}$ & $3 ; 9$ & $2 ; 0$ \\
\hline RYL & $5 ; 11$ & $\mathrm{M}$ & $5 ; 4$ & $0 ; 7$ \\
\hline \multicolumn{5}{|c|}{ Study 2} \\
\hline JSC & $4 ; 0$ & F & $2 ; 5$ & $1 ; 7$ \\
\hline LVT & $4 ; 1$ & F & $2 ; 1$ & $2 ; 0$ \\
\hline NTL & $4 ; 2$ & $\mathrm{~F}$ & $1 ; 11$ & $2 ; 3$ \\
\hline PLB & $4 ; 5$ & M & $2 ; 5$ & $2 ; 0$ \\
\hline FLP & $4 ; 6$ & M & $2 ; 1$ & $2 ; 4$ \\
\hline JCK & $4 ; 10$ & M & $2 ; 2$ & $2 ; 8$ \\
\hline LDN & $4 ; 10$ & M & $2 ; 0$ & $2 ; 10$ \\
\hline LCS & $4 ; 11$ & M & $2 ; 2$ & $2 ; 9$ \\
\hline DRS & $5 ; 0$ & M & $1 ; 8$ & $3 ; 4$ \\
\hline RNM & $5 ; 0$ & M & $1 ; 10$ & $3 ; 2$ \\
\hline $\mathrm{SZN}$ & $5 ; 0$ & $\mathrm{~F}$ & $2 ; 4$ & $2 ; 8$ \\
\hline VTL & $5 ; 6$ & $\mathrm{~F}$ & $1 ; 11$ & $3 ; 7$ \\
\hline
\end{tabular}

Note. All participants received Nucleus $24^{\circledR}$ cochlear implants. 
Apparatus, setting, and stimuli

Two computers were used to conduct the procedures in Studies 1 and 2. One computer was equipped with software developed specifically to manage the operant procedure and record the data $\left(\mathrm{AOLCAI}^{\circledR}\right.$; da Silva, de Souza, Bevilacqua, \& Savian, 2005). The other computer controlled the electrical stimulation generated by the cochlear implant. It was equipped with software manufactured by Cochlear Corporation ${ }^{\circledR}$ for programming the Nucleus $24^{\circledR}$ implant, which also provided the interface for the connection between the computer and the participant's speech processor.

The procedures were conducted in the hospital in a room equipped for cochlear implant programming. The experimental sessions were conducted with each participant individually between other clinical procedures. A speech therapist stayed at the right side of the participant and controlled the equipment for electrical stimulation. The experimenter (WRS) stayed behind the participant and monitored the child while the operant procedure was conducted. Occasionally, one or both parents could also stay in the room, depending on whether the child needed care during the session.

Auditory experimental stimuli derived from two sources: (1) environmental auditory stimuli generated by the software that managed the operant procedure, presented through computer sound boxes (77 $\mathrm{dB}$ intensity), and captured by the speech processor and (2) direct electrical stimulation of the electrodes in the cochlea.

Each auditory stimulus was presented in a series of 10 pulses. Each pulse duration was $1 \mathrm{~s}$, with $10 \mathrm{~ms}$ intervals between consecutive pulses. Thus, each sequence was conducted during a period of approximately $10 \mathrm{~s}$.

For the electrical stimulation of the cochlea, the participant's cochlear implant was connected to the computer equipped with the implant's interface, which was operated by the speech therapist. The speech processor was switched off (i.e., the participant no longer had access to environmental sounds). Each episode of electrical stimulation was presented during a $10 \mathrm{~s}$ period, during which three series of electrical stimulation were sent to the cochlea according to the strategy of codification adopted for each participant. The strategy defines, among other features, the speed of stimulation administered in pulses per millisecond. Thus, auditory and electrical stimulation had approximately the same total duration, although individual pulses had different durations.

Electrical stimulation was applied to electrodes 5, 15 , and 20, which were inserted into the basal, medial, and apical cochlear regions, respectively. Thus, during the procedure, low (basal), medium (medial), and high (apical) frequency sensations could be generated, depending on which electrode was stimulated. For each frequency, the intensity sensation varied according to the amount of electrical current applied to the electrode. The identification of the amount of electrical current was based on an arbitrary value classified as a unit of current (UC), ranging from 1 to 225 (Clark et al., 1997; Guedes et al., 2003) and approximately corresponding to values between 0.001 and 1.75 milliamperes (mA).

The programmed reinforcing consequences were 15 s periods of access to segments of a cartoon (Ice Age) shown on the computer screen. Each correct response was followed by the presentation of a segment of the cartoon.

\section{General procedure}

In both studies, a simple successive Go/No Go discrimination procedure was used to teach operant discrimination between the presence and absence of the auditory stimulus. Each study was conducted in two phases-Teaching (baseline) and Testing (threshold determination) - according to a single-subject design (Kazdin, 1982; Tawney \& Gast, 1984).

\section{Teaching phase: baseline}

In this phase, the task required a motor response in the presence (but not in the absence) of an auditory stimulus $\left(\mathrm{S}^{+}\right)$. Correct responses initiated the cartoon. Incorrect responses were followed by a $2 \mathrm{~s}$ blackout (extinction). A training block presented a mixed sequence of two trial types: $\mathrm{S}^{+}$(auditory stimulus) and $\mathrm{S}^{-}$(no auditory stimulus). Not more than three consecutive $\mathrm{S}^{+}$or $\mathrm{S}^{-}$trials occurred in sequence. Trials were separated by a $2 \mathrm{~s}$ ITI. In a $\mathrm{S}^{+}$trial, a response in the presence of the auditory stimulation turned the stimulus off and simultaneously initiated the reinforcing consequence. If no response occurred during the 10 pulses of stimulation, then the ITI began. In $\mathrm{S}^{-}$trials, the ITI began after an incorrect response or after $10 \mathrm{~s}$, whichever occurred first.

\section{Testing phase: threshold assessment}

When the operant discrimination was well established and stable (Sidman, 1960; see the stability criterion specified in the description of each study), the manipulation of the stimulus intensity was introduced according to the adapted staircase method (e.g., Levitt, 1971). Beginning with a value 5 UC lower than that used during baseline, the intensity was progressively reduced (descending series) until no responding occurred in the presence of the stimulation, indicating that it was not detected. The stimulus intensity was then increased until a response occurred in the presence of the electrical stimulation. Whenever possible, subsequent reversals in decreasing and increasing series were conducted to replicate the results.

\section{Study 1}

This study sought to systematically replicate (Sidman, 1960) the work of da Silva et al. (in press) and extend the threshold measurement to three electrodes. The Baseline Phase was the same as in da Silva et al. (in press). The Testing Phase was modified 
in two respects: (1) the stimulus intensity was modified during each new trial (not during each block with several trials), and (2) the steps for the manipulation of the electrical current were gradually reduced from $5 \mathrm{UC}$ to $1 \mathrm{UC}$, whereas in the previous study the magnitude of the increase or decrease was set to $5 \mathrm{UC}$. These features allowed the evaluation of whether the threshold measures could be reached more quickly and precisely than in the previous study, with children younger than those used in that study. Time economy is especially important when evaluating many electrodes in the same session.

\section{Methods}

\section{Participants}

As shown in Table 1, the participants were nine children (three girls and six boys) with prelingual bilateral neurosensory hearing loss who had received Nucleus $24^{\circledR}$ cochlear implants. Their hearing experience (time after implantation) varied from 7 months to 2 years 8 months.

\section{Settings and stimuli}

During the experimental sessions, a participant was seated, facing the computer screen, and had the computer mouse available for responding (see General Methods for other details).

\section{Procedure}

The computer screen was divided horizontally into two sections. The upper section was displayed in gray. The lower section was displayed in black. A 4 x $4 \mathrm{~cm}$ green square was shown in the bottom center of this area. A mouse click on the green square was recorded as a response. During the ITI, the entire screen was gray (i.e., no green square was available).

\section{Teaching phase}

\section{Baseline}

The children were initially pretrained to familiarize them with the task and then exposed to the discrimination training. During this phase, the participant's speech processor was on, and auditory stimuli were presented via the computer sound box.

\section{Pretraining}

The task consisted of positioning the mouse cursor over the green square and pressing the mouse button in the presence of sounds but not in their absence. Correct responses were followed by $15 \mathrm{~s}$ presentation of the cartoon, after which the entire screen turned gray, and the ITI began. Incorrect responses (in the absence of tones) initiated the ITI. When the ITI elapsed, the green square was presented again. In the presence of sounds presented simultaneously with the green square, another response resulted in an additional $15 \mathrm{~s}$ presentation of a novel segment of the cartoon. To teach the task without using oral instructions, the speech therapist presented a model of the correct response. She placed the cursor over the green square and pressed the mouse button only in the presence of sounds $\left(\mathrm{S}^{+}\right)$. She simultaneously asked the participant, with the aid of gestures, whether he or she detected the sounds. After five demonstration trials, the participant was given the mouse and was instructed to perform the task for the next five consecutive trials. If the participant did not press the mouse button during the sound presentation, then the speech therapist guided the child's hand to the mouse, moved the cursor until it was over the green square, and then pressed the child's hand over the button. If the participant did not respond appropriately after five trials with this prompting, then the physical instigation was gradually removed across successive sequences of five trials. The speech therapist would hold only the participant's wrist, without touching the mouse button. She would then hold only the participant's forearm. Eventually, she would only wait.

\section{Establishing auditory discrimination}

Trials with $\left(\mathrm{S}^{+}\right)$and without $\left(\mathrm{S}^{-}\right)$auditory stimulation were intermixed in 50-trial blocks, with 25 of each type. $\mathrm{S}^{+}$trials were initiated with the presentation of the green square on the computer screen along with the auditory pulses (for $10 \mathrm{~s}$ ). A response with the cursor over the green square interrupted the tones, turned off the green square, and initiated the presentation of a segment of the cartoon in the gray section of the screen. The cartoon presentation was followed by a $2 \mathrm{~s}$ ITI, during which the entire screen turned gray. If the mouse button was not pressed during the presentation of tone pulses, then the ITI screen was shown at the end of the $10 \mathrm{~s}$ interval. In Strials, no sounds were presented, and responses to the green square were followed by the immediate display of the ITI screen. In the absence of a response, the ITI screen was presented after $10 \mathrm{~s}$. The learning criterion was five consecutive minutes with a discrimination index (DI) equal to or greater than 0.9. The index was obtained by dividing responses in the presence of the auditory stimulus $\left(\mathrm{S}^{+}\right)$by the total number of responses. This index could vary from 0.0 to 1.0 , with 0.0 indicating responding exclusively during the $\mathrm{S}$, 0.5 indicating no discriminated responding (which occurred as frequently in $\mathrm{S}^{+}$as in $\mathrm{S}^{-}$trials), and 1.0 indicating exclusive responding in the presence of the $\mathrm{S}^{+}$. This stringent criterion ( $\left.\mathrm{DI} \geq 0.9\right)$ ensured that the participant learned to click on the green square in the presence of auditory stimulation and refrain from emitting the response in its absence. 


\section{Testing phase: determining auditory threshold}

Transition in baseline: substituting electrical stimulation for environmental sounds

Once the learning criterion was met, the participant's speech processor was turned off, and the device was connected to the interface. Thus, environmental sounds were no longer accessible, and electrical stimulation was sent directly to the cochlea. During this phase, electrode 15 (medial cochlea) was stimulated. The stimulus intensity was set to half of the range between the threshold and maximum auditory comfort measures previously obtained for each participant in the sessions that regulated the implant via clinical procedures. This intensity was sufficient for stimulus detection. Blocks of 10 trials (five $\mathrm{S}^{+}$and five $\mathrm{S}^{-}$) were conducted. The criterion was the completion of one block with $100 \%$ correct responses $(\mathrm{DI}=1.0)$ under electrical stimulation.

\section{Stimulus intensity manipulation}

When the baseline discrimination was accurate, the manipulation of the electrical current began. In this phase, only $\mathrm{S}^{+}$trials were presented, separated by the ITI. A correct response was followed by the cartoon presentation, ITI, and next trial. The absence of a response was followed by the ITI after $10 \mathrm{~s}$. The same electrode 15 was stimulated, and the initial intensity was $5 \mathrm{UC}$ lower than the baseline value. The intensity decreased for each trial, starting with a descending series in which the current decreased by 5 UC for each trial until the participant failed to respond during a trial (interpreted as a failure to detect the stimulus). In the subsequent trials, the stimulus intensity increased (reversal) by $3 \mathrm{UC}$ per trial until the participant again detected the stimulus. In a subsequent reversal, the intensity decreased by 2 UC per trial until the subject again failed to detect the stimulus. Finally, the intensity began to increase in successive steps of $1 \mathrm{UC}$ per trial until a response occurred. The intensity value in operation immediately before the first failure in stimulus detection was defined as the electrical stimulus threshold (cf. Clark et al., 1997) for electrode 15.

The same procedure was then conducted to determine the threshold for electrodes 5 and 20, in this order, without any other baseline revisions. For both electrodes, the initial intensity was $10 \mathrm{UC}$ lower than that applied to electrode 15. A 2 min interval followed the evaluation with each electrode, during which the speech therapist programmed the software for the next electrode.

\section{Results and discussion}

All nine children completed the procedure. During pretraining, the first modeling trials were sufficient for children to understand the task, and no additional prompting was necessary. Figure 1 presents the cumulative frequency of the responses in the presence $\left(\mathrm{S}^{+}\right)$and absence $(\mathrm{S})$ of the auditory stimulus in the Baseline Phase. All participants learned the simple successive discrimination. Four participants (GRL, RYL, VTR, and RDG) reached the learning criterion during the first block of 50 trials. Three participants (LCD, LHR, and GNV) showed accurate discrimination during the second block. Two participants (GLR and BRN) showed accurate discrimination during the third block. The cumulative curves show that in the presence of the auditory stimulus (solid lines), the response rate gradually increased, with positive acceleration typical of behavioral acquisition. In the absence of the stimulus (broken lines), some participants did not respond or responded at a low rate from the beginning and reached the learning criterion sooner. Other participants showed an initial increase in responding in the absence of the stimulus, which is typical of earlier instances of the extinction procedure, but eventually all of them showed negative acceleration in response rates in the $\mathrm{S}^{-}$trials. One exception was one participant (LCD) who seemed to discriminate between the $\mathrm{S}^{+}$and $\mathrm{S}^{-}$at the beginning of the two training blocks to which he was exposed but began to respond to both trial types later in each block. For most participants, the final section in the curves in the last block of trials suggested that the discrimination was well established for a period longer than the $5 \mathrm{~min}$ required by the criterion. The total amount of time required to acquire baseline varied from 11 to $16 \mathrm{~min}$ for participants who reached the criterion in the first block of trials and from 27 to $36 \mathrm{~min}$ for the other participants (Table 2).

Figure 2 shows the results from Phase 2 for individual participants. A clear pattern was observed across all participants. The first data-point represents the baseline intensity for each participant. Usually, after failing to detect the auditory stimulus at a particular intensity, responding recovered during reversal to a higher intensity, which was equal to or near the intensity in the trial immediately before a failure to detect the stimulus. For most participants, the effects of decreasing or increasing the stimulus intensity were replicated in successive reversals, strengthening the confidence in the measures.

Table 3 presents the intensities identified as the threshold for each electrode for individual participants. The results show interindividual variability, consistent with systematic findings regarding individual sensitivity to auditory stimulation (Ferguson et al., 2003). Thresholds varied among participants in the range of 155-174 UC (155-170 UC for the medial and basal electrodes and 160-174 UC for the apical electrodes). Because of this interindividual variability, determining individual thresholds as precisely as possible is necessary.

The thresholds also varied intraindividually from electrode to electrode, which was expected based on previous assessments with speaking patients (Morita, Naito, Hirai, Yamaguchi, \& Ito, 2003). The differences between the lowest and highest UC in the different 
electrodes for individual participants varied from 1 to 6 $\mathrm{UC}$ for seven of the participants. The other two participants presented differences equal to $14 \mathrm{UC}$ (RYL) and $15 \mathrm{UC}$ (LCD). These differences also strongly recommend the assessment of thresholds for each individual electrode using a reliable and cost-effective procedure.

The present procedure replicated the general results obtained by da Silva et al. (in press) for one electrode in the medial area of the cochlea and extended the previous findings to younger children and electrodes located in different sections of the cochlea.

The stimulus intensity increased or decreased by 5 UC per interval in da Silva et al. (in press), whereas the present study explored interval variations as short as 1 UC. The results suggest that the assessment in intervals of $5 \mathrm{UC}$ can be used for clinical implant fitting purposes.

The main limitation of the operant procedure used in the present study was its duration. Although the durations in Table 2 indicate that the entire task was accomplished in a short period of time, incidental observations suggested that the sessions were too long for this population. Fifty trials in a single session are well above the limits of the time span for attention and motivation in children at this age (e.g., Rovee-Collier \& Capatides, 1979; Gil, Oliveira, de Sousa, \& Faleiros, 2006; Oliveira \& Gil, 2008). Even when the baseline training was accomplished within a single block of trials, the tests required many more trials, considering the number of intensity values being assessed multiplied by three electrodes. During the relatively long exposure

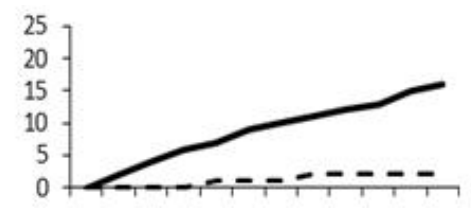

RYL
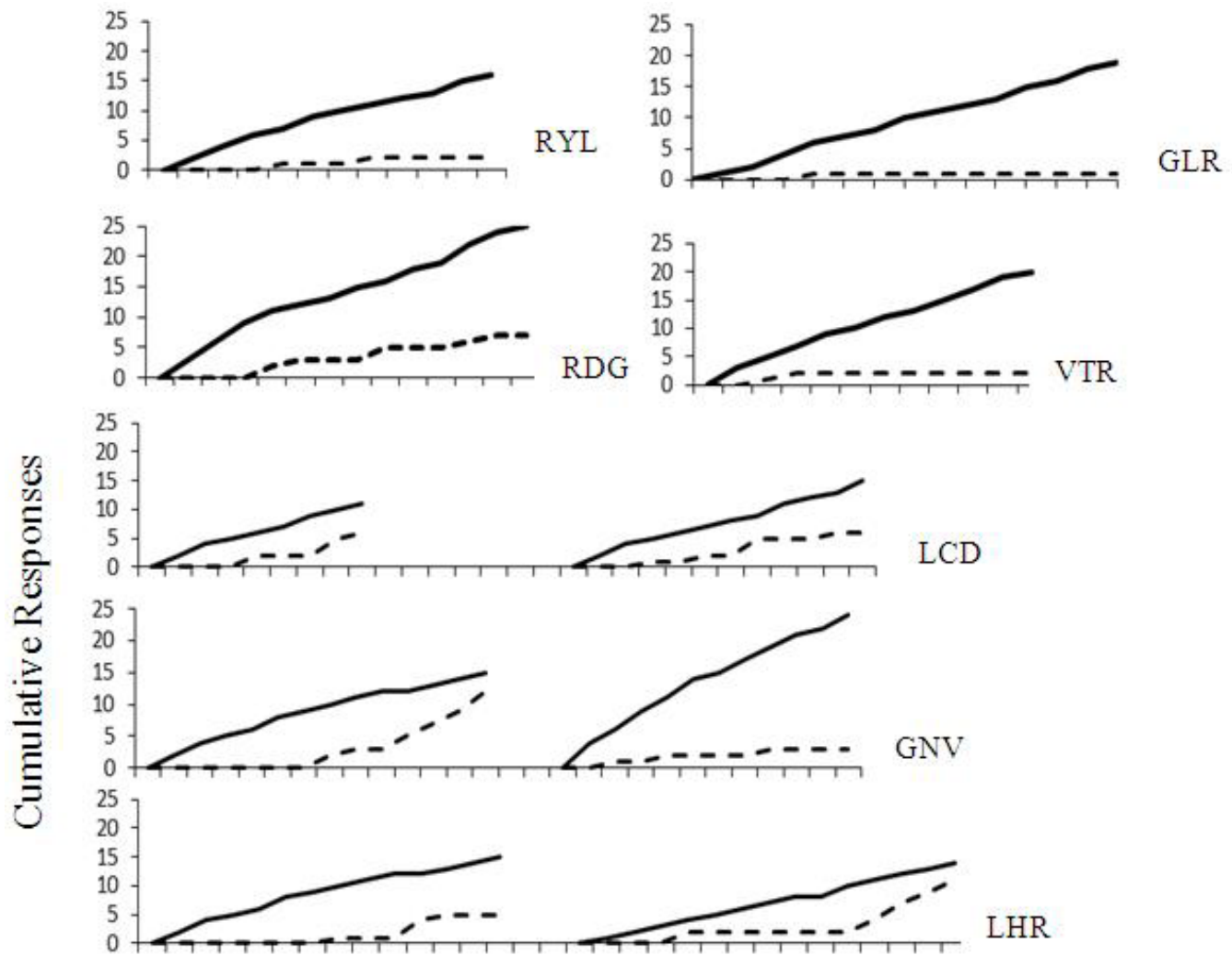

LHR
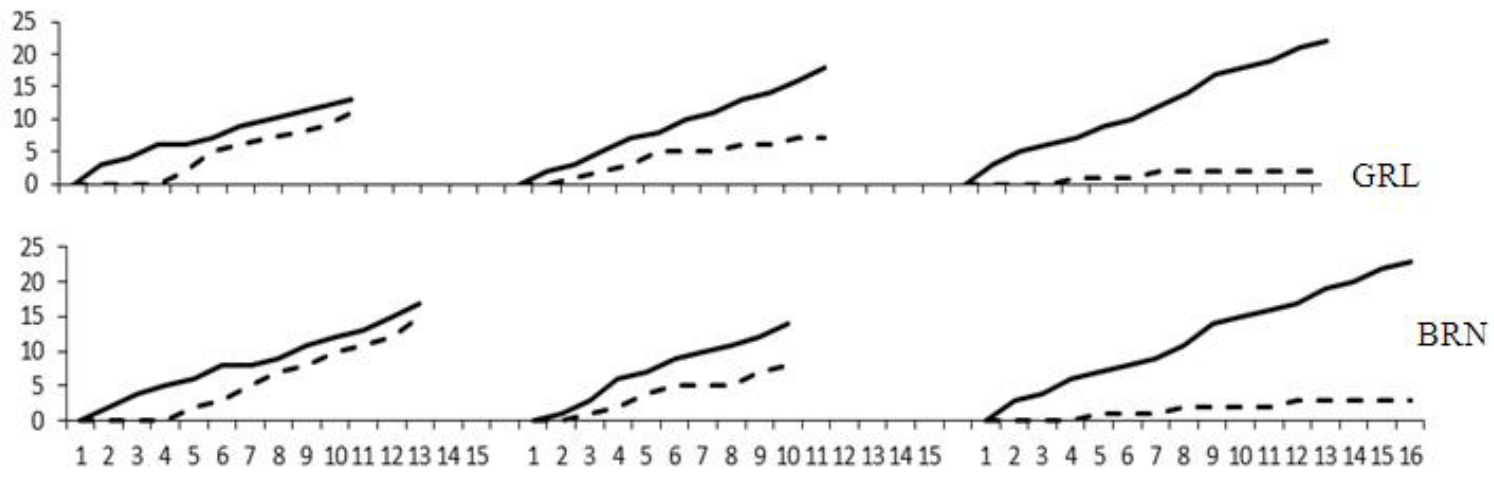

Time (min)

Figure 1. Cumulative responses in the baseline of simple discrimination (Phase 1) in Study 1. Solid lines indicate responses during auditory stimulation $\left(\mathrm{S}^{+}\right)$. Broken lines correspond to responses in the absence of stimulation $\left(\mathrm{S}^{-}\right)$. 
Table 2. Total time (min) to complete Phase 1 (Baseline) and Phase 2 (Testing: threshold determination) in Studies 1 and 2.

\begin{tabular}{|c|c|c|c|}
\hline Participant & Baseline (min) & Testing (min) & Total (min) \\
\hline \multicolumn{4}{|c|}{ Study 1} \\
\hline GRL & 34 & 11 & 45 \\
\hline GNV & 24 & 13 & 37 \\
\hline LHR & 27 & 12 & 39 \\
\hline RDG & 13 & 14 & 27 \\
\hline VTR & 11 & 12 & 23 \\
\hline LCD & 19 & 15 & 34 \\
\hline BRN & 36 & 14 & 50 \\
\hline GLR & 16 & 11 & 27 \\
\hline RYL & 11 & 13 & 24 \\
\hline \multicolumn{4}{|c|}{ Study 2} \\
\hline JSC & 8 & 11 & 19 \\
\hline LVT & 8 & 8 & 16 \\
\hline NTL & 15 & 12 & 27 \\
\hline PLB & 8 & 10 & 18 \\
\hline FLP & 16 & 10 & 26 \\
\hline JCK & 8 & 12 & 20 \\
\hline LDN & 8 & 9 & 17 \\
\hline LCD & 8 & 10 & 18 \\
\hline DRS & 8 & 9 & 17 \\
\hline RNM & 8 & 8 & 16 \\
\hline SZN & 8 & 7 & 15 \\
\hline VTL & 8 & 7 & 15 \\
\hline
\end{tabular}

period, the participants showed decreasing interest in the task (despite the opportunity to watch the cartoon) and engaged in concurrent, sometimes inappropriate behaviors. Thus, the programmed consequences lost their potentially reinforcing value, probably because of satiation or competition with the response cost. Adjustments in the procedure would be needed to maintain the children's behavior without causing them any discomfort. For efficiency in a clinical setting, the procedure should require less time; thus, both the acquisition phase and test phase should be abbreviated while maintaining high discrimination accuracy. Study 2 investigated this alternative.

\section{Study 2}

Considering that children with implants usually have enough experience with frequent routines conducted by speech therapists, including familiarity with the electrical stimulation in the cochlea, the present study evaluated the efficacy of a procedure that was much shorter than that used in Study 1. For this purpose, (1) pretraining was omitted, (2) training began directly with electrical stimulation of the cochlea (omitting the initial training with sounds captured by the speech processor), (3) the number of trials in a training block was reduced, and (4) the stimulus intensity varied in intervals of $5 \mathrm{UC}$.

\section{Methods}

\section{Participants}

As shown in Table 1, the participants were 12 children with prelingual profound bilateral neurosensory deafness, aged 4 years to 5 years 6 months, and users of the Nucleus $24^{\circledR}$ cochlear implant. Auditory deprivation varied from 1 year 8 months to 2 years 5 months. Experience with the implant varied from 1 year 7 months to 3 years 7 months.

\section{Settings, apparatus, and stimuli}

These were the same as those used in Study 1.

\section{Procedure}

Teaching phase: baseline. Initially, the speech therapist demonstrated how to perform the task (i.e., she placed the cursor over the green square and pressed the mouse button in the presence of sounds $\left[\mathrm{S}^{+}\right]$but not in 


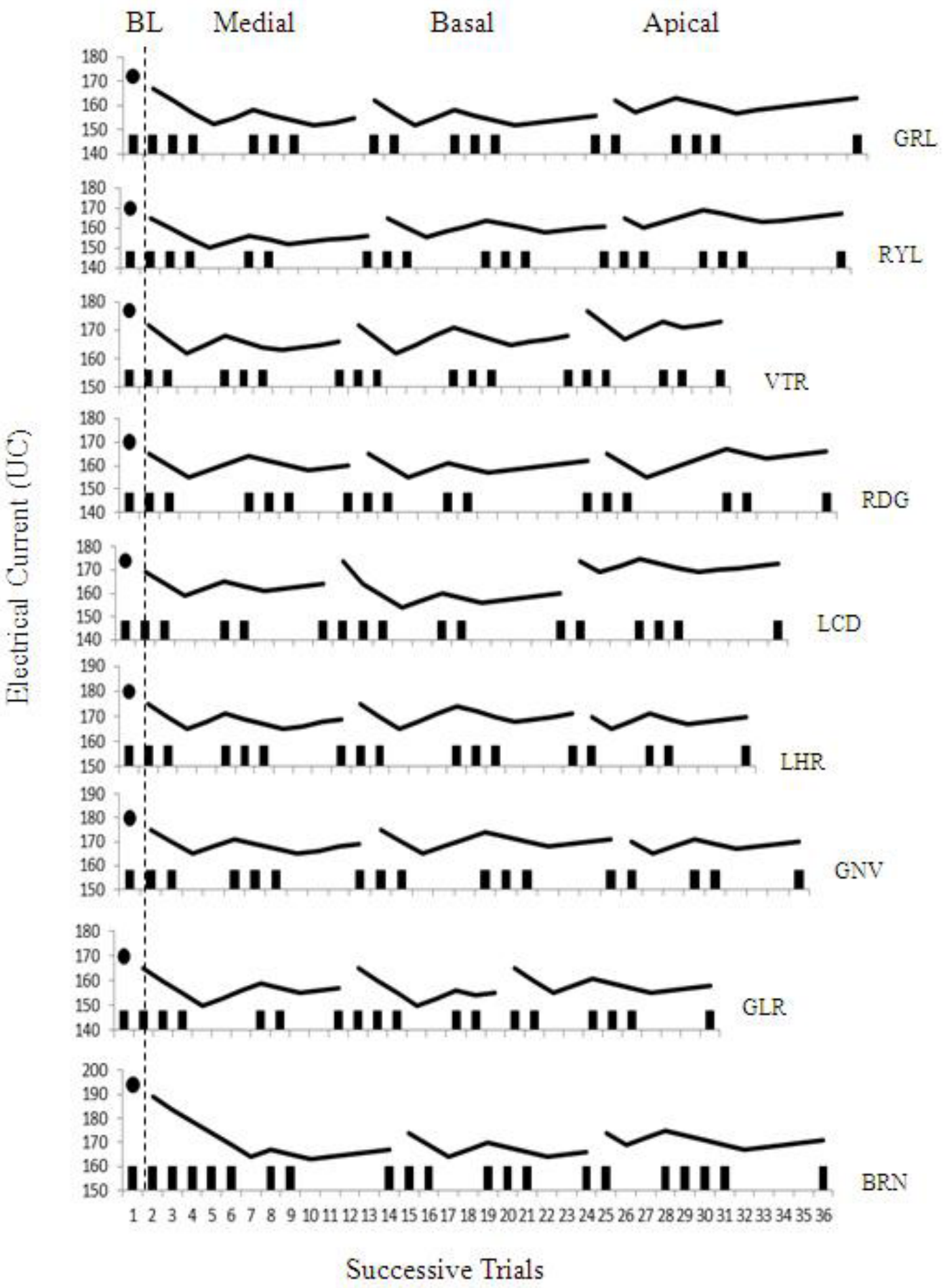

Figure 2. Values of electrical current during descending and ascending series of current manipulation for the determination of auditory thresholds in Phase 2 (Study 1) for each electrode (medial, basal and apical). The first data-point on the left corresponds to the baseline intensity.

their absence) and waited until the participant did the same. Electrical stimulation was sent to electrode 15. The stimulus intensity in the initial trials was based on previous clinical evaluations, and all participants showed detection of the stimulus. The training block had 30 trials, 15 with electrical stimulation $\left(\mathrm{S}^{+}\right)$and 15 without electrical stimulation $\left(\mathrm{S}^{-}\right)$. The two trial types were distributed in a semi-random order, avoiding single alternation. The learning criterion was a DI equal to or greater than $90 \%$ of correct responding, and the training block was repeated until the criterion was reached. 
Table 3. Values of electrical current (UC) suggested as auditory thresholds for individual participants for each electrode (medial, basal, and apical) in Studies 1 and 2. The values correspond to the lowest intensity that reliably maintained discriminated responding (Clark et al., 1997). See the behavioral patterns in Figures 2 and 4.

\begin{tabular}{|c|c|c|c|}
\hline Participant & Medial Electrode & Basal Electrode & Apical Electrode \\
\hline \multicolumn{4}{|c|}{ Study 1} \\
\hline GRL & 157 & 157 & 162 \\
\hline RYL & 155 & 160 & 169 \\
\hline VTR & 167 & 167 & 172 \\
\hline RDG & 160 & 160 & 167 \\
\hline LCD & 164 & 159 & 174 \\
\hline LHR & 170 & 170 & 170 \\
\hline GNV & 170 & 170 & 170 \\
\hline GLR & 155 & 155 & 160 \\
\hline BRN & 169 & 169 & 174 \\
\hline \multicolumn{4}{|c|}{ Study 2} \\
\hline SZN & 150 & 150 & 150 \\
\hline RMN & 150 & 145 & 150 \\
\hline LVT & 165 & 160 & 160 \\
\hline VTL & 145 & 150 & 145 \\
\hline LCS & 145 & 145 & 150 \\
\hline JSC & 140 & 135 & 135 \\
\hline LDN & 155 & 160 & 155 \\
\hline PLB & 140 & 140 & 145 \\
\hline DRS & 145 & 140 & 135 \\
\hline JCK & 155 & 145 & 145 \\
\hline NTL & 165 & 155 & 165 \\
\hline FLP & 145 & 150 & 145 \\
\hline
\end{tabular}

Testing phase: determining auditory threshold

After the participant reached the baseline criterion, the next block introduced the manipulation of the stimulus intensity, first in descending order, then in ascending order, followed by a second reversal in descending order. The stimulus intensity changed for every trial, and the magnitude of change was fixed at $5 \mathrm{UC}$. The criterion for the reversal in the stimulus intensity was the first trial without stimulus detection in a descending series and the first trial with stimulus detection in an ascending series. The same procedure was repeated with electrodes 5 and 20, in this order. A 2 min interval between the assessment of one electrode and the next was used for preparing the equipment.

\section{Results and discussion}

\section{Baseline}

All participants acquired the discrimination between the presence and absence of electrical stimulation in the cochlea. Figure 3 shows that 10 of the 12 participants reached the learning criterion during the first block of 30 trials in a single session that lasted approximately 8 min (Table 2). Two other participants (NTL and FLP) completed the baseline phase during the second training block, with the session lasting from 15 to 16 min. The cumulative curves show that children began responding in both trial types $\left(\mathrm{S}^{+}\right.$, solid lines; $\mathrm{S}^{-}$, broken lines), but across trials the response rates tended to increase during $\mathrm{S}^{+}$trials and decrease and eventually stop completely during $\mathrm{S}^{-}$trials. The discrimination process replicated that observed with participants in Study 1 and also that obtained with other populations, including typically developing children (e.g., Gil et al., 2006). These results suggest that the modified procedure is appropriate for teaching baseline discrimination and may be useful in clinical settings. They also contribute to the literature on discrimination learning in children, extending the generalizability of the data to the auditory discrimination of electrical stimulation via a cochlear implant. 


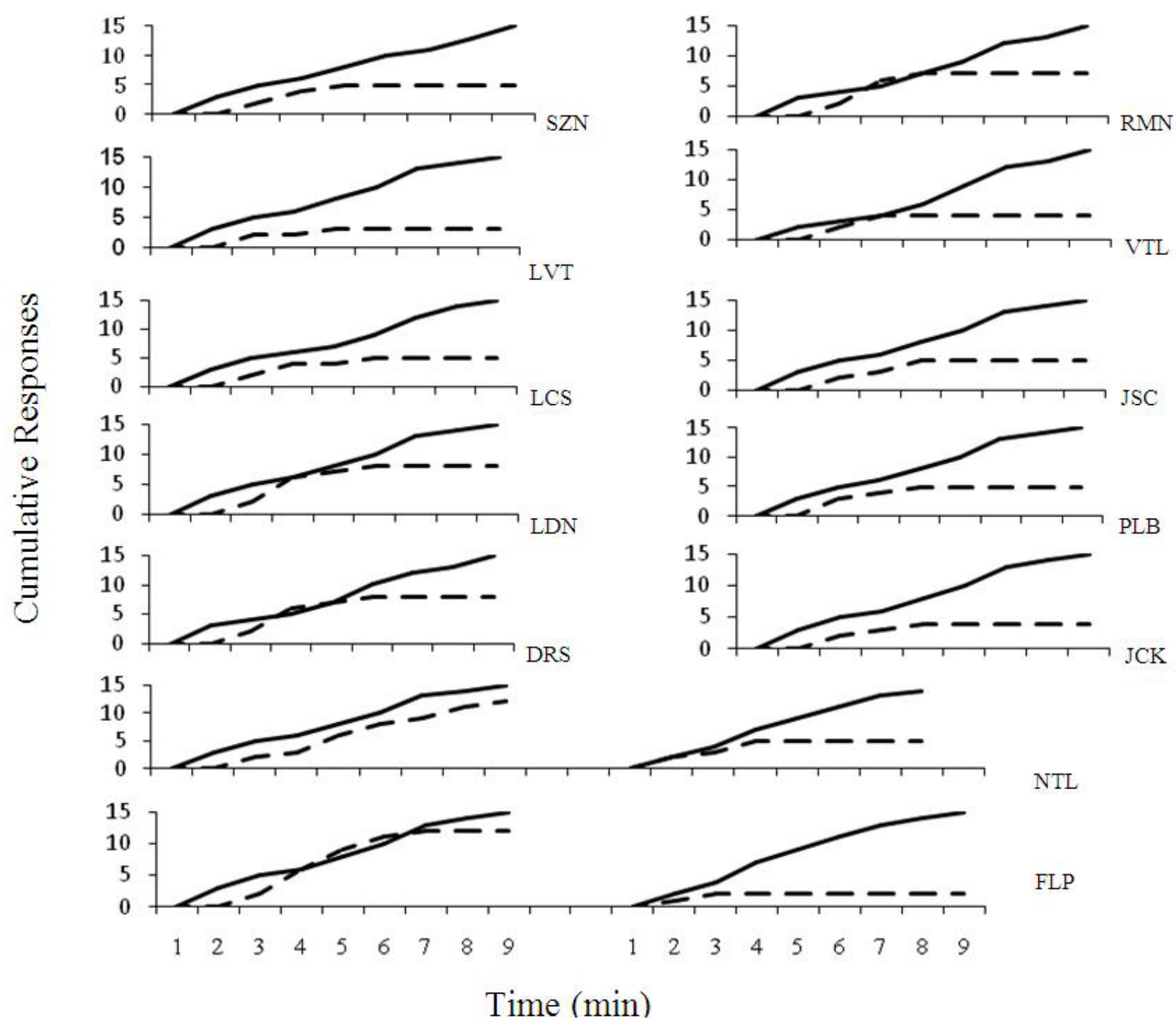

Figure 3. Cumulative responses in the baseline of simple discrimination (Phase 1) in Study 2. Solid lines indicate responses during auditory stimulation $\left(\mathrm{S}^{+}\right)$. Broken lines correspond to responses in the absence of stimulation $\left(\mathrm{S}^{-}\right)$.

\section{Testing phase}

All participants completed the procedure within 7 to 12 min (Table 2, bottom section). Figure 4 shows the changes in responding along successive changes in the intensity of the electrical stimulation for individual participants. The intensity was gradually reduced as long as the participant continued to respond. The stimulus intensity usually decreased by several steps below the baseline value before a detection failure occurred. When a child failed to detect the stimulus presentation, the intensity was again increased until a response occurred (stimulus detection). For all participants, only one step in the reversal to a higher intensity $(+5 \mathrm{UC})$ resulted in stimulus detection. The stimulus detection when the intensity increased demonstrates that auditory discrimination was intact. Thus, the lack of responding was a failure in stimulus detection. A new reversal to the lower intensity replicated the absence of responding. The intensity values suggested as the threshold for each participant and for each electrode are presented in Table 3 (bottom section). Similar to Study 1 , the results indicate interindividual differences and also different thresholds for the different electrodes for a single individual. The threshold values in this study ranged from 135 to 165 UC (140-165 UC for the medial electrodes and 135-165 UC for the basal and apical electrodes). One participant (SZN) presented the same threshold for all three electrodes. Eight of 12 participants showed a variation of $5 \mathrm{UC}$ (only one step in intensity change) between the three electrodes. Three participants (DRS, JCK, NTL) presented a variation as large as $10 \mathrm{UC}$ (two steps).

The adjustments in the procedure improved its efficacy compared with Study 1. The acquisition of operant discrimination and its maintenance during the tests were reliably replicated among participants. The shorter sessions required less effort and may have prevented the effects of satiation. Incidental observations suggested that on-task behavior lasted longer, and the incidence of disruptive behaviors decreased compared with Study 1. 


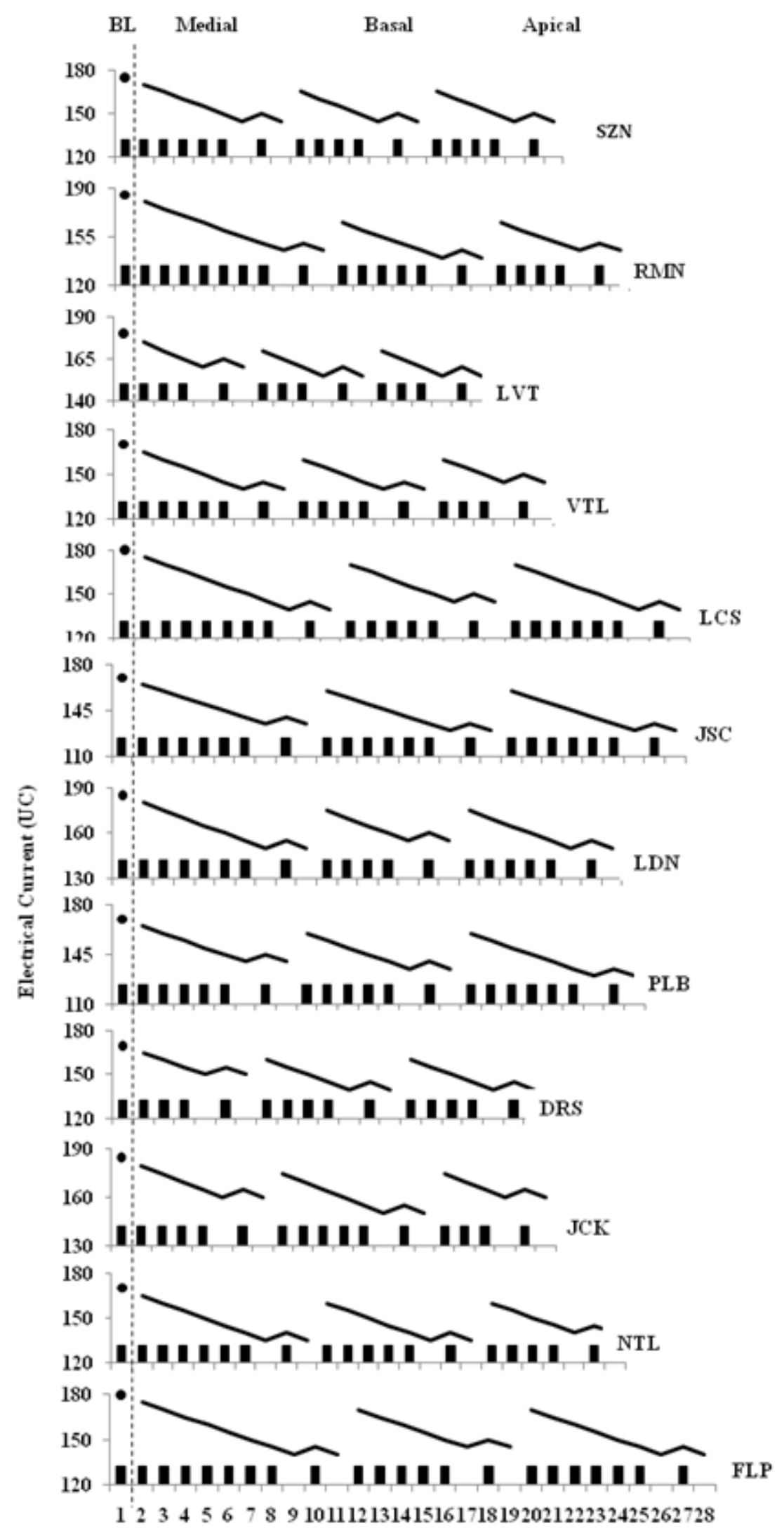

Successive trials 


\section{General discussion}

The results of these two studies demonstrated improvements in the operant preparation for the reliable measurement of the auditory threshold in 4- to 6-yearold children with neurosensory deafness who use cochlear implants. The final version of the procedure (Study 2) can be quickly applied while maintaining the child's attention and interest in the task. As shown in Table 2, the procedure duration decreased from an average of $33 \mathrm{~min}$ (range, 27 to $50 \mathrm{~min}$ ) in Study 1 to approximately $18 \mathrm{~min}$ (range, 15 to $27 \mathrm{~min}$ ) in Study 2 .

This design incorporates features suggested by findings from experimental research with young children, such as short sessions and powerful reinforcing events (e.g., Gil et al., 2006; Olsho, Schoon, Sakai, Turpin, \& Sperduto, 1982; Oliveira \& Gil, 2008; RoveeCollier \& Capatides, 1979; Simmons \& Lipsitt, 1961).

In both studies, the measures suggested as auditory thresholds varied among the three electrodes for each individual participant (Table 3). Such intraindividual variability was also found by Ferguson et al. (2003). These authors suggested that variables related to this variation may be inherent to the device (e.g., phase duration, stimulation mode, order of electrodes, electrode location, and so on) or related to the biological condition of the residual auditory nervous tissue (i.e., number of cells and activity level). Thus, the variability found in the present studies replicates findings from previous cochlear implant research. The sources of individual variability must be identified and understood because variability has implications for the quality of speech perception and speech recognition by implantees and can consequently interfere with the acquisition and intelligibility of their own speech.

One potential weakness of the measures obtained in the present studies could be the threshold accuracy. One could argue that the scale interval of 5 UC was too large and that a more precise measure could be situated at some point between the two extremes of this interval. However, the behavioral data from Study 1 (Figure 2) suggested that intervals shorter than $5 \mathrm{UC}$ are not well discriminated through a cochlear implant. These results are generally consistent with those obtained using other measurement procedures (Wieringen \& Wouters, 2001; Zimmerling \& Hochmair, 2002).

The present findings recommend the use of the operant procedure and experimental design (i.e., baseline followed by threshold assessment) for clinical applications with children in this age range. With the exception of language delay, these children presented behavioral patterns characteristic of typically developing children, such as following instructions (even if gestural or signed), remaining on task in the presence of professionals (with or without the presence of parents), enjoying the video clips used as reinforcing consequences, and learning simple discrimination tasks (e.g., Lionello De-Nolf, Mcllvane, Canovas, de Souza, \& Barros, 2008; Plenderleith, 1956). However, considering that earlier implantation is associated with greater efficacy in language acquisition (Anderson et al., 2004; Svirsky et al., 2004), implantation has been conducted with much younger children. To meet their needs related to their behavioral repertoires, the present procedure will require additional adjustments with regard to response mode and reinforcing consequences.

\section{Acknowledgements}

The research program was supported by PRONEX/ FAPESP (grant no. 03/09928-4) and postdoctoral scholarship to WRS. DGS and MCB received fellowships from Conselho Nacional de Desenvolvimento Científico e Tecnológico (National Council for Scientific and Technological Development [CNPq]). The authors are affiliated with the National Institute on Science and Technology on Behavior, Cognition and Teaching supported by FAPESP (grant no. 08/57705-8) and CNPq (grant no. 573972/2008-7). We thank Márcia Y.T. Kimura for conducting the electrical stimulation of the cochlea during the experimental procedures and Richard Serna for comments on the manuscript. We also thank the children and their families for their participation.

\section{References}

Almeida-Verdu, A.C., Huziwara, E.M., de Souza, D.G., de Rose, J.C., Bevilacqua, M.C., Lopes, J., Jr., Alves, C.O., \& McIlvane, W.J. (2008). Relational learning in children with deafness and cochlear implants. Journal of the Experimental Analysis of Behavior, 89, 407-424.

American Speech-Language-Hearing Association. (2004). Cochlear Implants [Technical Report]. Retrieved from www.asha.org/policy.

Anderson, I., Weichbold, V., D’Haese, P.S.C., Szuchnik, J., Quevedo, M.S., Martin, J., Dieler, W.S., \& Phillips, L. (2004). Cochlear implantation in children under the age of two: what do the outcomes show us? International Journal of Pediatric Otorhinolaryngology, 68(4), 425-431.

Berg, K.M., \& Smith, M.C. (1983). Behavioral thresholds for tones during infancy. Journal of Experimental Child Psychology, 35, 409-425.

Bevilacqua, M.C., Costa Filho, O.A., \& Moret, A.L.M. (1997). Reabilitação e implante coclear [Rehabilitation and cochlear implant]. In O. Lopes Filho (Ed.), Tratado de fonoaudiologia (pp. 401-414). São Paulo: Roca.

Bevilacqua, M.C., Costa Filho, O.A., \& Moret, A.L.M. (2003). Implante coclear em crianças [Cochlear implantation in children]. In A.H. Campos \& O.O. Costa (Eds.), Tratado de otorrinolaringologia (pp. 268-277). São Paulo: Roca.

Blough, D.S. (1958). A method for obtaining psychophysical threshold from the pigeon. Journal of the Experimental Analysis of Behavior, 1, 31-43.

Clark, G.M., Cowan, R.S.C., \& Dowell, R.C. (1997). Speech processor programming. In G.M. Clark, R.S.C. Cowan, \& R.C. Dowell (Eds.), Cochlear implantation for infants and children: advances (pp. 149-170). San Diego: Singular.

Clevenger, A.C., \& Restrepo, D. (2006). Evaluation of the validity of a maximum likelihood adaptive staircase procedure for measurement of olfactory detection threshold in mice. Chemical Senses, 31, 9-26.

Cornsweet, T.N. (1962). The staircase-method in psychophysics. American Journal of Psychology, 75, 485-491. 
da Silva, J.A., \& Ribeiro Filho, N.P. (2006). Avaliação e mensuração de dor: pesquisa, teoria e prática [Assessment and measurement of pain: research, theory, and practice]. Ribeirão Preto: FUNPEC Editora.

da Silva, W.R., de Souza, D.G., Bevilacqua, M.C., Kimura, M., \& Lopes, J., Jr. (in press). Medidas operantes de limiar auditivo de crianças surdas pré-linguais usuárias de implante coclear. [Operant measurement of auditory threshold in prelingually deaf users of cochlear implants] Psicologia: Reflexão e Crítica, 24(2).

da Silva, W.R., de Souza, D.G., Bevilacqua, M.C., \& Savian, J. (2005). Avaliação operante de limiar e conforto auditivo em implantados [Evaluation of operant limiar and auditory comfort in implant users]. Software for research. Instituto Nacional da Propriedade Industrial (INPI): Rio de Janeiro.

da Silva, W. R., de Souza, D.G., de Rose, J.C., Bevilacqua, M.C., \& McIlvane, W.J. (2006). Relational learning in deaf children with cochlear implant. Experimental Analysis of Human Behavior Bulletin, 24, 1-8.

Ferguson, W.D., Collins, L.M., \& Smith, D.W. (2003). Psychophysical threshold variability in cochlear implant subjects. Hearing Research, 180, 101-113.

Feitosa, M.A.G. (1996). Teoria e métodos em psicofísica [Theory and methods in psychophysics]. In L. Pasquali (Ed.), Teoria e métodos de medida em ciências do comportamento (pp. 43-71). Brasília: Editora da UnB/INEP.

Fulton, R.T., \& Spradlin, J.E. (1971). Operant audiometry with severely retarded children. International Journal of Audiology, 10, 203-211.

Gerken, G.M., \& Sandlin, D. (1977). Auditory reaction time and absolute threshold in cat. Journal of the Acoustical Society of America, 61, 602-607.

Gescheider, G.A. (1997). Psychophysics: the fundamentals (3rd edition). Mahwah, NJ: Lawrence Erlbaum.

Gil, M.S.C.A., Oliveira, T.P., de Sousa, N.M., \& Faleiros, D.A.M. (2006). Variáveis no ensino de discriminação para bebês /Variables in teaching discriminations to infants]. Psicologia Teoria e Pesquisa, 22, 143-152.

Guedes, M.C., Gomes, M.V.S.G., Sant'Ana, S.B.G., Peralta, C.G.O., Brito Neto, R.V., Sanches, T.G., Bento, R.F., \& Castillo, A.M. (2003). Medidas de telemetria de resposta neural em usuários de implante coclear multicanal. Arquivos Internacionais de Otorrinolaringologia, 7, 197-204.

Kazdin, A.E. (1982). Single case research designs: methods for clinical and applied settings. New York: Oxford University Press.

Langemann, U., Gauger, B., \& Klump, G.M. (1998). Auditory sensitivity in the great tit: perception of signals in the presence and absence of noise. Animal Behavior, 56, 763-769.

Levitt, H. (1971). Transformed up-down methods in psychoacoustics. Journal of the Acoustical Society of America, 49 ( Suppl. 2), 467-477.

Lionello-DeNolf, K., McIlvane, W.J., Canovas, D.S., de Souza, D.G., \& Barros, R.S. (2008). Reversal learning set and functional equivalence in children with and without autism. Psychological Record, 58, 15-36.

Moore, J.M., Wilson, W.R., \& Thompson, G. (1977). Visual reinforcement of head-turn responses in infants under 12 months of age. Journal of Speech and Hearing Disorders, 42, 328-334.

Morita, T., Naito, Y., Hirai T, Yamaguchi, S., \& Ito, J. (2003). The relationship between the intraoperative ECAP threshold and postoperative behavioral levels: the difference between postlingually deafened adults and prelingually deafened pediatric cochlear implant users. European Archives of Oto-rhino- laryngology, 260, 67-72.

Nicolelis, M.A.L. (2001). Action from thoughts. Nature, 409, 403-407.

Oliveira, T.P., \& Gil, M.S.C.A. (2008). Condições experimentais facilitadoras para a aprendizagem de discriminação por bebês. [Experimental conditions to facilitate infants discimination learning] Psicologia: Teoria e Pesquisa, 24, 5-18.

Olsho, L.W., Schoon, C., Sakai, R., Turpin, R., \& Sperduto, V. (1982). Auditory frequency discrimination in infancy. Developmental Psychology, 18, 721-726.

Pfingst, B.E., \& Morris, D.J. (1993). Stimulus features affecting psychophysical detection thresholds for electrical stimulation of the cochlea: II. Frequency and interpulse interval. Journal of the Acoustical Society of America, 94, 1287-1294.

Plenderleith, M. (1956). Discrimination learning and discrimination reversal learning in normal and feebleminded children. Journal of Genetic Psychology, 88, 107-112.

Primus, M.A., \& Thompson, G. (1985). Response strength of young children in operant audiometry. Journal of Speech and Hearing Research, 28, 539-547.

Rizzi, F.M.L., \& Bevilacqua, M.C. (2003). Efeito do número e localização dos eletrodos na cóclea na percepção da fala de indivíduos pós-linguais implantados [Effects of number and location of electrodes in the cochlea on speech perception in post-lingually implant users]. Revista Brasileira de Otorrinolaringologia, 69 , 364-369.

Rovee-Collier, C.K., \& Capatides, J.B. (1979). Positive behavioral contrast in 3-month-old infants on multiple conjugate reinforcement schedules. Journal of the Experimental Analysis of Behavior, 32, 15-27.

Sidman, M. (1960). Tactics of scientific research: evaluating experimental data in psychology. New York: Basic Books.

Simmons, M.W., \& Lipsitt, L.P. (1961). An operant-discrimination apparatus for infants. Journal of the Experimental Analysis of Behavior, 4, 233-235.

Sinnott, J.M., Pisoni, D.B., \& Aslin, R.N. (1983). A comparison of pure tone auditory thresholds in human infants and adults. Infant Behavior \& Development, 6, 3-17.

Skinner, B.F. (1953). Science and human behavior. New York: Macmillan.

Svirsky, M.A., Robbins, A.M., Kirk, K.I., Pisoni, D.B., \& Miyamoto, R.T. (2000). Language development in profoundly deaf children with cochlear implants. Psychological Science, 11, 153-158.

Svirsky, M.A., Teoha, S.W., \& Neuburger, H. (2004). Development of language and speech perception in congenitally, profoundly deaf children as a function of age at cochlear implantation. Audiology \& Neuro-Otology, 9, 224-233.

Tawney, J.W., \& Gast, D.L. (1984). Single subject research in special education. Columbus, $\mathrm{OH}$ : Merrill.

Thai-Van, H., Truy, E., Charasse, B., Boutitie, F., Chanal, J.M., Cochard, N., \& Collet, L. (2004). Modeling the relationship between psychophysical perception and electrically evoked compound action potential threshold in young cochlear implant recipients: clinical implications for implant fitting. Clinical Neurophysiology, 115, 2811-2824

Wieringen, A., \& Wouters, J. (2001). Comparison of procedures to determine electrical stimulation threshold in cochlear implant users. Ear and Hearing, 22, 528-538.

Zimmerling, M.J., \& Hochmair, E.S. (2002). ECAP recordings in Ineraid patients: correlations with psychophysical measures and possible implications for patient fitting. Ear \& Hearing, 23, 81-91. 